\title{
A QUANTITATIVE STUDY ON EVIDENCE OF VARICOSE VEINS AMONG DIFFERENT OCCUPATIONAL BACKGROUNDS IN THE CITY OF MOSUL IRAQ
}

\author{
Hanady Jabar Mahmood ${ }^{1}$, Radhwan Hussein Ibrahim ${ }^{1 *}$, Mohammad Faris Abdulghani ${ }^{2}$ and Zainab Faisal \\ Al-Zaidy ${ }^{1}$
}

${ }^{1}$ Department of Clinical Nursing sciences, College of Nursing, University of Mosul, City of Mosul, Iraq; ${ }^{2}$ Department of Clinical Nursing Sciences, College of Nursing, Ninevah University, City of Mosul, Iraq;

\author{
Corresponding author: Radhwan Hussein Ibrahim \\ Email: prof.dr.radhwan@uomosul.edu.iq.
}

\begin{abstract}
The present study focuses on evidence of varicose veins (VV) in subjects on different parameters like occupations, gender, and smoking habits etc. in the City of Mosul, Iraq. A quantitative study was performed at Mosul Teaching Hospital between November 2019 and February 2020. Total sample size was 1052 in numbers. Subjects were mainly among different occupations like Nurses, address, Policemen, and teachers. Selected subjects were physically examined on general parameters who agreed to engage in this study. The rate of overall $V V$ prevalence among different occupational backgrounds in the City of Mosul was found to be 200/1052 (19\%). It was observed that the percentage of men (49\%) and women (51\%) and the mean age of the participants was (39.1+3.1). The entire study analyses the effects of various parameters like obesity (BMI), gender, age, smoking habit, and alcohol consumption etc on prevalence of $\mathrm{VV}$. Additionally study also concludes that more occupational standing which has significant contributions in prevalence of $V V$ can be prevented by sitting or walking at frequent intervals whenever is appropriate. So, by improving clinical practices the incidences of vascular diseases may be reduced.
\end{abstract}

Keywords: Varicose vein, Prevalence, Occupational Standing, Venous disorder

\section{INTRODUCTION}

Varicose vein may be the main reason of severe pain in lower limbs and of other complications in patients. This might lead to involvement of surgical and other management procedures eventually challenges health care expenses and finally reduces the work efficiency of employee ${ }^{1}$. Each vein of human body comprises a series of uniform valve system that prevents returning of blood from veins to lower limbs and feet. Weakening of these valves results in leakage of blood and it leads to its previous position and get accumulates over or below the valves. Because of blood accumulation, the veins get expanded and swollen prominently and results in $\mathrm{VV}^{2}$. Prevalence of $\mathrm{VV}$ is different significantly in men and women. It varies from 10 to 30 percent in men and 25 to 55 percent in women. Various studies were conducted to estimate the prevalence of VV In Saudi Arabia. A study conducted, found the prevalence of VV among teachers was $48.2 \%$. In another study the prevalence of VV in nurses of Egypt was found to be $18.2 \%$. In the United States, more than $23 \%$ of adults were experienced varicose veins, and $80 \%$ of them were female with the average age of 40 years old ${ }^{3}$. Physiologically linked several factors such as obesity, age, pregnancy, menopause etc. are responsible for developing $\mathrm{VV}$ in women as compared to men. Excessive alcohol consumption can also lead to this condition due to vasodilation and effect of gravity and blood viscosity. It can also be diagnosed clinically by examining the physical condition of patients in standing position and asking about the severity of aches ${ }^{4-6}$. To check the normal functionality of valves patients may be suggested to go for ultrasound to see the evidence of any blood clot. The present study deals with the effect of various parameters on prevalence of VV in different subjects. It also suggests chances of $\mathrm{VV}$ occurrence can be reduced by improving clinical practices.

\section{METHOD}

The study was conducted after obtaining an ethical and scientific agreement from the Ethical Research Committee in Nineveh Health Directorate. The detailed objectives of the study and procedure involved was explained to the patients and consent form from the patients were taken before examination and data collection. A cross-sectional study was performed in the radiography department (Doppler ultrasound) at Al-Salam Teaching Hospital between November 2019 and February 2020. During the study period, (1100) clients visited the radiology department (Doppler ultrasound) for examination, (1052) clients of them were agreed to participate in the study. A non-probability sample was selected accidentally. The patients were examined for multi symptomatology related to $\mathrm{VV}$ from different occupational backgrounds and needed long-standing profile (Nurses, Addresses, Policeman, Teachers) of 20 years old and above. Patients with chronic diseases such as DM, HT, heart diseases, liver diseases, and renal diseases 
were excluded from this study. The study instruments were composed of, Demographic information, anthropometry measurement, medical data, healthy social habitus smoking status, and alcohol intake.

BMI of the patients were calculated by taking Weight and height measurements. The following formula. BMI=Weight $(\mathrm{Kg}) /$ height $(\mathrm{M}) 2$. SECA measured weight; this scale (SN: 3101615) was manufactured for UNICEF using technology developed in Australia, and family history of VV was recorded. The leg area of patients was observed after holding them for ten minutes in standing position. The color doppler ultrasound scanner (for sale-MSLCU08 MODEL NO:1400024000) at the National Institute for Health and Care Excellence (NICE) was used for diagnosis ${ }^{7}$. The Clinical-Etiology-Anatomy-Pathophysiology (CEAP) classification standard (Table 3 ) for chronic venous disorders was used in this study for recording clinical research results. It was well explained to the patients to avoid any confusion to their end ${ }^{8}$.

The blood flow through the veins was tested by using doppler ultrasound which worked on the principle of bouncing high-frequency sound waves (ultrasound) off circulating red blood cells. On the other hand, regular ultrasound uses sound waves to produce images but can't show blood flow and, $A$ it is used to estimate how fast blood flows by measuring the rate of changes in its pitch (frequency).

The doppler categorizes the varicose vein into many grades. Grade I when no dilated intrastromal veins and reflux in spermatic cord veins of the inguinal region during Valsalva manoeuvre. Grade II when prominent veins at the upper pole of testis and reflux at upper pole veins during Valsalva manoeuvre. Grade III when no significant dilatation in supine position dilated veins up to lower pole of testis seen only in standing position and reflux at lower pole veins during Valsalva manoeuvre. Grade IV dilated veins even in supine position and reflux during Valsalva manoeuvre. Grade $\mathbf{V}$ when dilated veins and reflux without Valsalva manoeuvre. Statistical analysis was done by using SPSS version 25 . Numbers and percentages were the variables used to present the study results. Chi-square test was applied to determine the significance of variable to VV.

\section{RESULTS}

The different occupational backgrounds like Nurses, Addresses, Policeman, and Teachers are having $19 \%$ of prevalence rate of VV in the City of Mosul. The man and women percentage of prevalence was $(49 \%)$ and $(51 \%)$ respectively (Table 1A). Most of the patients were with the mean age $(39.1+3.1)$. Results indicated that as per the BMI more than 25 had $11 \%$ prevalence of VV. The study also reflects that long working hours of (more than 8 hours /day) resulted in significant evidence of VV (Table 1B). The smoking habit was for the sample members with VV were $(17.7 \%)$ and alcohol consumption were $(40.5 \%)$. Percent distribution of various symptoms among male and female which were observed along with VV (Table 2). It was noticed that maximum patients (total of $45 \%$ ) with edema were of $23 \%$ in male and $22 \%$ in female respectively. And minimum it was for pulmonary embolism and bleeding with total of $1 \%$ both in male and female.

Table 1A: Total percentage of subjects with and without varicose veins for gender and age groups

\begin{tabular}{|c|c|c|c|c|c|}
\hline \multirow[b]{2}{*}{ Variables } & \multicolumn{2}{|c|}{ Total Prevalence of VV } & \multicolumn{2}{|c|}{$19 \%$} & \multirow[b]{2}{*}{ P-Value } \\
\hline & $N(1052)$ & With VV & Without VV & $\mathrm{X}^{2}$ & \\
\hline \multicolumn{6}{|l|}{ Gender } \\
\hline Male & 516 (49\%) & $84(8 \%)$ & $432(92 \%)$ & \multirow{3}{*}{4.910} & \multirow{2}{*}{0.02} \\
\hline Female & $536(51 \%)$ & $116(11 \%)$ & $420(89 \%)$ & & \\
\hline \multicolumn{5}{|l|}{ Age Group } & \\
\hline $20-25 Y$ & $53(5 \%)$ & (20) $38 \%$ & (33) 62\% & & \\
\hline $26-30 Y$ & $126(12 \%)$ & (24) $19 \%$ & (102) $81 \%$ & & \\
\hline $31-35 Y$ & $131(12.5 \%)$ & (26) $20 \%$ & (105) $80 \%$ & & \\
\hline $36-40 Y$ & $179(17 \%)$ & (30) $17 \%$ & (149) 83\% & & \\
\hline $41-45 Y$ & 347 (33\%) & (60) $17 \%$ & (287) 83\% & \multirow{3}{*}{13.41} & \multirow{3}{*}{0.01} \\
\hline $46-50 Y$ & $216(20.5)$ & (40) $18.5 \%$ & (176) $81.5 \%$ & & \\
\hline Total & 1052 & 200 & 852 & & \\
\hline
\end{tabular}


Table 1B: Prevalence of varicose veins considering different variables

\begin{tabular}{|c|c|c|c|c|c|}
\hline Variables & N (1052) & With VV & Without VV & $\mathrm{X} 2$ & P-Value \\
\hline \multicolumn{6}{|l|}{ BMI } \\
\hline$>25$ & 347 (33\%) & $40(11.5 \%)$ & $307(88.5 \%)$ & & \\
\hline$<25$ & 705 (77\%) & $160(22.7 \%)$ & $569(77.3 \%)$ & 16.86 & 0.000 \\
\hline \multicolumn{6}{|l|}{ Job } \\
\hline Nurses & $285(27 \%)$ & $60(30 \%)$ & $225(70 \%)$ & & \\
\hline Addresses & $221(21 \%)$ & $42(21 \%)$ & $179(79 \%)$ & & \\
\hline Policeman & $273(26 \%)$ & $50(25 \%)$ & $223(75 \%)$ & & \\
\hline Teacher & 273 (26\%) & $48(24 \%)$ & $225(76 \%)$ & 1.21 & 0.7 \\
\hline \multicolumn{6}{|l|}{ Family history } \\
\hline Yes & 652 (62\%) & $110(16.9 \%)$ & 542 (83.1\%) & & \\
\hline No & $400(38 \%)$ & $90(22.5 \%)$ & 278 (77.5\%) & 8.58 & 0.003 \\
\hline \multicolumn{6}{|l|}{ Smoking } \\
\hline Yes & $610(58 \%)$ & 108(17.7\%) & $502(82.3 \%)$ & & \\
\hline No & $442(42 \%)$ & $92(20.8 \%)$ & $350(79.2 \%)$ & 1.60 & 0.2 \\
\hline \multicolumn{6}{|l|}{ Alcohol } \\
\hline Yes & $42(4 \%)$ & $17(40.5 \%)$ & $25(59.5 \%)$ & & \\
\hline No & 1010(96\%) & 183(18.1) & $827(81.9 \%)$ & 13.0 & 0.000 \\
\hline \multicolumn{6}{|l|}{ Standing } \\
\hline$>8$ & 537 (51\%) & $32(6 \%)$ & $505(94 \%)$ & & \\
\hline$<8$ & $488(49 \%)$ & $168(34.4)$ & $320(65.6 \%)$ & 131.9 & 0.000 \\
\hline \multicolumn{6}{|l|}{ Limb affected } \\
\hline Rt Limb & $80(40 \%)$ & & & & \\
\hline Lt Limb & $60(30 \%)$ & & & & \\
\hline Both & $60(30 \%)$ & & & & \\
\hline Total & $200(100 \%)$ & & & & \\
\hline
\end{tabular}

Table 2: Percent distribution of symptoms among male and female

\begin{tabular}{llll}
\hline Symptoms & Male & Female (\%) & Total (\%) \\
\hline Edema & $46(23 \%)$ & $44(22 \%)$ & $90(45 \%)$ \\
Lipodermatosclerosis & $10(5 \%)$ & $6(3 \%)$ & $16(8 \%)$ \\
Pigmentation & $14(7 \%)$ & $20(10 \%)$ & $34(17 \%)$ \\
Eczema & $14(7 \%)$ & $16(8 \%)$ & $30(15 \%)$ \\
Healed ulcer & $2(1 \%)$ & $2(1 \%)$ & $4(2 \%)$ \\
Active ulcer & $2(1 \%)$ & $4(2 \%)$ & $6(3 \%)$ \\
Thrombophlebitis & $6(3 \%)$ & $10(5 \%)$ & $16(8 \%)$ \\
Pulmonary embolism & $1(0.5 \%)$ & $1(0.5 \%)$ & $2(1 \%)$ \\
Bleeding & $1(0.5 \%)$ & $1(0.5 \%)$ & $2(1 \%)$ \\
\hline
\end{tabular}


Malaysian Journal of Public Health Medicine 2021, Vol. 21 (3): 36-41

Table 3: Percent distribution of clinical classification of varicose veins $(n=200)$

\begin{tabular}{lc}
\hline Clinical classification of CEAP & N (\%) \\
\hline C0: No visible veins & $132(66 \%)$ \\
C1: Reticular veins & $12(6 \%)$ \\
C2: Varicose veins & $8(4 \%)$ \\
C3: Edema & $28(17 \%)$ \\
C4a: Pigmentation or eczema & $6(3 \%)$ \\
C4b: Lipodermatosclerosis & $2(1 \%)$ \\
C5: Healed venous ulcer & $4(2 \%)$ \\
C6: Active venous ulcer & $2(1 \%)$ \\
\hline
\end{tabular}

\section{DISCUSSION}

Varicose veins are sometimes considered as a cosmetic problem unless it causes any pain and discomfort, but this is a serious issue with patients with severe aches and associated other complications and problems. In many cases it's gives invitation to blood related other problems. Treatment of varicose veins may vary depending on its severity, patients age, physical activity etc. It's sometimes limited to self- treatment based on symptoms or it may need surgically implemented method of blocking and removing affected veins. The current study focuses on variables responsible for VV like age, sex, occupation, patients' history, BMl etc.

These examinations highlighted that the prevalence of $\mathrm{VV}$ is $(19 \%)$ table $(1 \mathrm{~A})$. This substantiates previous findings in the literature. The prevalence of varicose veins is $14 \%$ in the adult population of Saudi Arabia. (9-14). The percentage of prevalence in Finland was $13.5 \%$, $15 \%$ in United states of America and $36.7 \%$ in Turkey ${ }^{15-17}$. The differences in the percentage of prevalence of $\mathrm{V} V$ suggests that lifestyle of people may be is one of the reasons of it. In our study, from total of 1052 patients 49\% of them were males, and $51 \%$ of them were females. If We look at the prevalence of $\mathrm{VV}$ in male and female it was found to be $11 \%$ in female and $8 \%$ in male. It has been shown in our study that varicose veins are more common in women may be due to various factors associated so it can be concluded that female sex is at significant risk factor ${ }^{18-20}$.

Lee et. al (1999) $)^{21}$ also revealed that prevalence of $\mathrm{VV}$ was $40 \%$ in men and $32 \%$ in women ${ }^{21}$. Opposite to it was reported by (Ciardullo et. $\mathrm{al})^{22}$ that women $(35.2 \%)$ than in men $(17 \%)$. It can be said from the various studies that higher prevalence of $\mathrm{VV}$ in women may be due to various physiological conditions associated with women and in men may be due to other reasons ${ }^{22}$.

Looking at the observations of increasing age, it can also be correlated with the occurrence of $\mathrm{VV}^{8}$, 23-27. Epidemiological trials revealed that patients with higher abdominal obesity showed increased $\mathrm{CVI}$ and decreased VTE ${ }^{28}$. Both VTE and CVI due to venous stasis is believed to be predisposed to obesity. On the other hand, central obesity which causes more intra-abdominal pressure showed more evidence of VV. This is supported by findings of present study where a longitudinal pattern of VV was observed in patients with higher BMI.It was also observed in case of over weighted patients they had higher intestinal pressures contributing to reflux ${ }^{29}$.

Considering one of the important factors despites of age and gender, smoking is related with venous insufficiencies in all age group were found with evidence $\mathrm{VV}^{30}$. And one other study suggested by ${ }^{31}$ that only epidemiological review reflected presence of $\mathrm{VV}$ with smoking in adults (Table 1B). In the present study we have also tried to corelate the existence of $\mathrm{VV}$ with different occupations like traffic police, civil servants, cotton staff in hospital and medical professionals like nurses. In one of the studies conducted by kendia et al. 50 out of 273 patients (18.3\%) of traffic police staff reported to have varicose veins and, comparing it to another study only $4.17 \%$ of traffic police staff were observed with VV of legs and $2.91 \%$ of VV of hands. These evidence of $\mathrm{VV}$ in Traffic police staff may be due to their long hrs of standing services ${ }^{32}$. We observed that long working hours occupational risk factor was significant $(X 2=131.9, p<0.000)$, and substantially can be correlated with the lower limb VV. It was supported by studies conducted on civil servants in Germany and Denmark that long hrs of standing are directly correlated with evidence of $\mathrm{VV}$ with proportional probability of 
$1.75^{33}$. Further a study conducted on cotton staff for presence of $\mathrm{VV}$ and its comparison was made between staff who stood-up and work and who does not stand up and work, and it was concluded a significant number of staff had evidence of $\mathrm{VV}^{34}$. 35 .

Lastly, one of the studies conducted on 203 nurses with a set of questionnaire and physical examination using CEAP standards. The results showed that $145(71.4 \%)$ of nurses had evidence of $\mathrm{VV}$ which can be considered a significant percentage. So, we can conclude that long working hrs for any occupation may develop VV in subjects of any gender.

\section{CONCLUSIONS}

Varicose vein is one of the venous disorders and present in patients with different occupation, gender, age and with other habits. The prevalence of Varicose veins was found to be (19\%) in the City of Mosul, Iraq. A significant risk factor for the varicose veins is gender, age, increased BMI, family history, alcohol consumption, and extended time of standing. It is suggested that persons working for long hours can be made to sit or walk in between to avoid evidence of VV. It can also be concluded that selfanalysis and symptomatic treatment and improvement in clinical practices can decrease chances of VV occurrence.

\section{ETHICAL CONSIDERATIONS COMPLIANCE WITH ETHICAL GUIDELINES}

Ethical permission was obtained from the Nineveh medical Ethics Committee (NMEC) with letter No. 524 dated 14 January 2020. The participants were informed about the research's purpose and ensured anonymity and confidentiality of the information. A written informed, voluntary participation consent was obtained from each participant.

\section{FUNDING}

This research did not receive any grant from funding agencies in the public, commercial, or non-profit sectors.

\section{AUTHOR'S CONTRIBUTIONS}

Study concept: Hanady Jabbar and Radhwan Hussein; Writing the original draft: Hanady Jabbar, Mohammad Faris, and Radhwan Hussein; Data collection: Zainab Faisal; Data analysis: Radhwan Hussein, Reviewing the final edition: All authors.

DISCLOSURE STATEMENT: The authors report no conflict of interest.

\section{ACKNOWLEDGEMENTS}

We want to thank the ethical Research committee in the City of Mosul Health Directorate and Deanship of Nursing College at University of Mosul for facilitating the current research process.

\section{REFERENCES}

1. Shakya R, Karmacharya RM, Shrestha R, Shrestha er al . Varicose veins and its risk factors among nurses at Dhulikhel hospital: a cross sectional study. BMC nursing.2020;19(1):8.

2. Wall R, Garcia G, Läubli T, Seibt R, Rieger et al. Physiological changes during prolonged standing and walking considering age, gender and standing work experience. Ergonomics. 2020(justaccepted):1-23.

3. Meneses-Claudio B, Alvarado-Diaz W, Roman-Gonzalez A. Detection of suspicions of varicose veins in the legs using thermal imaging. Int. J. Adv. Comput. Sci. Appl.2019;10:431-5.

4. Falovic R, Nambiar M, Boekel et al. Varicose veins causing tibial nerve compression in the tarsal tunnel. BMJ case reports. 2019 May 10;12(5).

5. Raetz J, Wilson M, Collins K. Varicose veins: Diagnosis and treatment. American family physician. 2019;99(11):682-8.

6. Bhargavi R, Iragavarapu T, Kumar AA. A Rare Case of Primary Upper Extremity Varicose Veins. Indian Journal of Cardiovascular Disease in Women WINCARS. 2019;4(01):029-31.

7. Marsden G, Perry M, Kelley K, Davies AH. Diagnosis and management of varicose veins in the legs: summary of NICE guidance. Bmj.2013 Jul 24;347.

8. Eklöf B, Rutherford RB, Bergan JJ, Carpentier et al. Revision of the CEAP classification for chronic venous disorders: consensus statement. J Vasc Surg.2004; 40(6):1248-52.

9. Stanhope JM. Varicose veins in a population of lowland New Guinea. Int J Epidemiol.1975;4(3):221-5.

10. Richardson JB, Dixon M. Varicose veins in tropical Africa. Lancet. 1977;1(8015):791-2.

11. Capitão LM, Menezes JD, Gouveia-Oliveira A. Caracterização epidemiológica da insuficiência venosa crónica em Portugal [Epidemiological characterization of chronic venous insufficiency in Portugal]. Acta Med Port. 199;9(2-3):69-77.

12. Laurikka J, Läärä E, Sisto T, Tarkka et al . Misclassification in a questionnaire survey of varicose veins. J Clin Epidemiol. 1995;48(9):1175-8. 
13. Diehm C. Epidemiologie und Pathogenese der Varikosis [Epidemiology and pathogenesis of varicosities]. Herz. 1989;14(5):267-73. German.

14. Bawakid KO, Al-Raddadi RM, Sabban SS, Alturky et al Prevalence of chronic venous insufficiency in the Saudi adult population. Saudi Med J. 2005;26(2):2259.

15. Mäkivaara LA, Jukkola TM, Sisto T, Luukkaala T, Hakama et. al Incidence of varicose veins in Finland. Vasa. 2004;33(3):159-63.

16. Fan CM. Venous pathophysiology. Semin Intervent Radiol. 2005;22(3):157-61.

17. Komsuoğlu B, Göldeli O, Kulan K, Cetinarslan et.al Prevalence and risk factors of varicose veins in an elderly population. Gerontology. 1994;40(1):2531.

18. Vandy F, Wakefield TW. Varicose veins: evaluating modern treatments, with emphasis on powered phlebectomy for branch varicosities. Interventional Cardiology 2012;4(5):527.

19. Jawien A. The influence of environmental factors in chronic venous insufficiency. Angiology 2003;54 Suppl 1:S19-31. their relationship with risk factors in nurses of the Birjand University of Medical Sciences Hospital's. J.of birjand university of medical sciences. 2005 ;15;12(1):9-15.

26. Clark A, Harvey I, Fowkes FG. Epidemiology and risk factors for varicose veins among older people: cross-sectional population study in the UK. Phlebology. 2010;25(5):236-40.

27. Bihari I, Tornoci L, Bihari P. Epidemiological study on varicose veins in Budapest. Phlebology. 2012;27(2):77-81.

28. Ageno W, Piantanida E, Dentali et al.Body mass index is associated with the development of the post-thrombotic syndrome. Thromb Haemost. 2003;89(2):305-9.

29. van Rij AM, De Alwis CS, Jiang et al . Obesity and impaired venous function. Eur J Vasc Endovasc Surg. 2008;35(6):73944.

30. Robertson L, Evans CA, Fowkes FG. Epidemiology of chronic venous disease. Phlebology. 2008;23(3):103-11.

31. Prajapati P, Modi K, Rahul K, Kedia G. A study on sociodemographic profile and health profile of traffic police personnel of Ahmedabad city, Gujarat, India. Population .Int $J$ Health Sci Res.

20. Karmacharya RM, Prajapati L, Rai SJIJoV, Surgery et.al.2Rikk; żjšş\$ment of varicose veins among the traffic police of Kathmandu Metropolitan City, Nepal. Indian J Vasc Endovasc

Surg. 2019;6(2):107.

Evans CJ, Fowkes FG, Ruckley CV, Lee et.al. Prevalence of varicose veins and chronic venous insufficiency in men and women in the general population: Edinburgh Vein Study. J Epidemiol Community Health.1999;53(3):149-53.

22. Iannuzzi A, Panico S, Ciardullo et. al.Varicose veins of the lower limbs and venous capacitance in postmenopausal women: relationship with obesity. J Vasc Surg. 2002;36(5):965-8.

23. Beebe-Dimmer JL, Pfeifer JR, Engle JS, Schottenfeld D. The epidemiology of chronic venous insufficiency and varicose veins. Ann Epidemiol. 2005 ;15(3):175-84

24. Robertson L, Evans C, Fowkes FG. Epidemiology of chronic venous disease. Phlebology. 2008;23(3):103-11

25. Nasiri-Foourg A, Kazemi T, Nakhaii N, Kazemi N. Lower limb varicose veins and
32. Sridher S, Thulasiram S, Rishwanth R, Sakthivel G, Rahul V, Uma Maheswari R. Health status of traffic police personnel in Chennai city. Alcohol. 2017;20(67):48-2.

33. Allesøe K, Søgaard K, Aadahl M, Boyle E, Holtermann A. Are hypertensive women at additional risk of ischaemic heart disease from physically demanding work? Eur J Prev Cardiol. 2016 ;23(10):1054-61.

34. Angeline GN, Bobby J. Work related musculoskeletal disorders among adolescent girls and young women employees of textile industries in Tamil Nadu, India - a comparative study. Int $J$ Adolesc Med Health. 2017;30(6):/j/ijamh.2018.30.issue6/ijamh-2016-0116/ijamh-20160116.xml.

35. Chen CL, Guo HR. Varicose veins in hairdressers and associated risk factors: a cross-sectional study. BMC Public Health. 2014;14(1):1-6. 